\title{
$\mathrm{Cr} / n-\mathrm{AIGaN} / \mathrm{GaN}$ Schottky Contact에서 높은 쇼트키 장벽 형성 메카니즘에 관한 연구
}

\author{
남효덕 ${ }^{1}$, 이영민 ${ }^{1}$, 장자순 ${ }^{1, a}$ \\ 1 영남대학교 전자공학과 및 LED-IT융합산업화 연구센터
}

\section{Formation Mechanism of a Large Schottky Barrier Height for $\mathrm{Cr}-\mathrm{AlGaN} / \mathrm{GaN}$ Heterostructure}

\author{
Hyo-Duk Nam ${ }^{1}$, Yeung-Min Lee ${ }^{1}$, and Ja-Soon Jang ${ }^{1, a}$ \\ ${ }^{1}$ Department of Electronic Engineering and LED-IT Fusion Technology Research Center (LIFTRC), \\ Yeungnam University, Gyeongsan, 712-749, Korea
}

(Received February 25, 2011; Revised March 4, 2011; Accepted March 4, 2011)

\begin{abstract}
We report on the formation mechanism of large Schottky barrier height (SBH) of nonalloyed $\mathrm{Cr}$ Schottky contacts on strained A10.25Ga0.75N/GaN. Based on the current-voltage (I-V) and capacitance-voltage $(\mathrm{C}-\mathrm{V})$ data, the SBHs are determined to be $1.98( \pm 0.02)$ and $2.07( \pm 0.02) \mathrm{eV}$ from the thermionic field emission and two-dimensional electron gas (2DEG) calculations, respectively. Possible formation mechanism of large SBH will be described in terms of the formation of $\mathrm{Cr}-\mathrm{O}$ chemical bonding at the interface between $\mathrm{Cr}$ and $\mathrm{AlGaN} / \mathrm{GaN}$, low binding-energy shift to surface Fermi level, and the reduction of 2DEG electrons.
\end{abstract}

Keywords: Schottky contact, AlGaN-GaN interface, Schottky barrier height

\section{1. 서 론}

알루미늄질화갈륨 $(\mathrm{AlGaN})$ 물질은 넓은 에너지 밴 드갭 (wide energy bandgap), 높은 포화전자속도 (electron saturated velocity), 높은 파괴전계 (high breakdown field) 등과 같은 우수한 성질로 인하여 고주파/고전력 소자와 광소자 연구에 널리 사용되고 있다 [1]. HEMT (high electron mobility transistor), HFET (heterostructure field effect transistor)와 같 은 $\mathrm{AlGaN}$ 계열의 우수한 소자성능을 갖는 전자소자를 개발하기 위해서는, 높은 쇼트키장벽 (High SBH)을 갖는 고품위 쇼트키 게이트 접촉 (Schottky gate contact) 형성에 대한 연구가 매우 필요하다.

a. Corresponding author; jsjang@ynu.ac.kr
Strained $\mathrm{AlGaN}-\mathrm{GaN}$ 이종접합구조에서 유발되는 강한 Polarization 효과는 높은 쇼트키장벽 형성에 기 여를 하기 때문에, 낮은 누설전류와 높은 파괴전압을 갖는 고성능 전자소자 개발에 적합하여 이에 대한 연 구가 활발히 진행되어져 왔다. 지금까지, $\mathrm{n}$ 형 쇼트키 장벽을 높이기 위해서 $\mathrm{AlGaN} / \mathrm{GaN}$ 이종접합이 갖는 일 함수 (Work function) 보다 높은 일함수를 갖는 금속을 Schottky gate 물질로 연구되어져 왔다 [2-8]. 원칙적 으로, 높은 일함수를 갖는 금속을 이용하여 $\mathrm{n}$ 형 $\mathrm{AlGaN} / \mathrm{GaN}$ Schottky contact을 형성하는 것이 일반 적이지만, Lin 연구그룹의 연구결과에 의하면 [4], 금 속의 일함수가 증가할수록 쇼트키 금속과 $\mathrm{AlGaN} / \mathrm{GaN}$ 표면 도너 (surface donor)전자들의 wave-function coupling이 감소하는 현상으로 인하여 쇼트키장벽은 오히려 감소한다는 연구결과를 보고하였다. 이는 높 
은 일함수를 갖는 금속을 쇼트키 접촉물질로 사용하 는 것이 $\mathrm{AlGaN} / \mathrm{GaN}$ 이종접합 쇼트키소자에서는 효 과적이지 못할 수도 있다는 것을 의미한다. 또한, $\mathrm{AlGaN} / \mathrm{GaN}$ 이종접합 쇼트키 접촉에서 쇼트키장벽의 높이는 2DEG (two dimensional electron gas)전자농도 에 영향을 받는데, 이것은 스트레인을 받는 $\mathrm{AlGaN} / \mathrm{GaN}$ 표면에 존재하는 도너성향의 표면준위 (donor-like surface state)와 Polarization에 기인한 전하 (polarization-induced charge)가 $2 \mathrm{DEG}$ 전자형성에 관여하기 때문이다 [2,5]. 이 외에도, $\mathrm{AlGaN} / \mathrm{GaN}$ Schottky 장벽형성에는 3족 공공 (Group III vacancies) 형성에 의한 표면 Fermi level이 VBM (valance band maximum)방향으로의 이동에 의한 것이 보고되었다 [8]. 하지만, $\mathrm{AlGaN} / \mathrm{GaN}$ 이종접합 구 조에는 $10^{18} \mathrm{~cm}^{-3}$ 이상의 도너 역할을 하는 산소가 포함 되어 있기 때문에 [9], 사실 쇼트키장벽 형성 원인에 대 해서는 아직 규명되어야 될 요소들이 많은 것이 사실이 다.

본 연구에서는 상대적으로 낮은 일함수를 갖는 $\mathrm{Cr}$ 을 쇼트키 금속으로 이용하여 높은 일함수를 갖는 고품위 Schottky contact을 보고하고자 한다. 또한, 쇼트키장벽 형성원인에 대하여 전류-전압, 커패시턴스-전압 특성과 XPS (X-ray photoelectron spectroscopy) 데이터를 이용 하여 논의하고자 한다.

\section{2. 실험 방법}

유기화상증착장비 (metalorganic chemical vapor deposition)를 이용하여 Sapphire 기판위에 $40 \mathrm{~nm}$ 두 께의 $\mathrm{GaN}$ buffer 층을 성장한 후, $2 \mu \mathrm{m}$ 두께로 undoped $\mathrm{GaN}$ 층을 성장시켰다. 이 위에 $\mathrm{Al}_{0.25} \mathrm{Ga}_{0.75} \mathrm{~N}$ 을 $20 \mathrm{~nm}$ 두께로 성장시켜, $\mathrm{AlGaN} / \mathrm{GaN}$ 이종접합층 을 형성하였다. $25 \%$ 의 $\mathrm{Al}$ 함유비율 (composition)은 X 선 회절방법 (X-ray diffraction)에 의하여 확인하였으며, 홀효과측정기로 얻은 $2 \mathrm{DEG}$ 농도 $\left(\mathrm{N}_{2 \mathrm{DEG}}\right)$ 는 $1.17 \times 10^{13}$ $\mathrm{cm}^{-2}$ 이었다. 쇼트키 접촉은 먼저, Schottky pattern형성 전에 아세톤, 메탄올, 증류수 (DI water)를 이용하여 각 각 5 분 간 표면세척을 시행하였으며, $\mathrm{AlGaN}$ 표면에 존 재하는 자연산화층을 제거하기 위하여 $\mathrm{HCl}: \mathrm{DI}$ (1:1) 용액을 이용하여 표면처리를 시행하였다. 쇼트키 및 오믹 패턴 구조는 그림 1 에 나타내었다. 각각의 패턴 은 Photolithography 방법에 의해서 형성하였으며, 30 $\mathrm{nm}$ 두께의 $\mathrm{Cr}$ 을 쇼트키 금속층으로, $\mathrm{Ti} / \mathrm{Al} / \mathrm{Pd} / \mathrm{Au}$ $(50 / 80 / 50 / 100 \mathrm{~nm})$ 를 오믹 (Ohmic) 금속층으로 이용

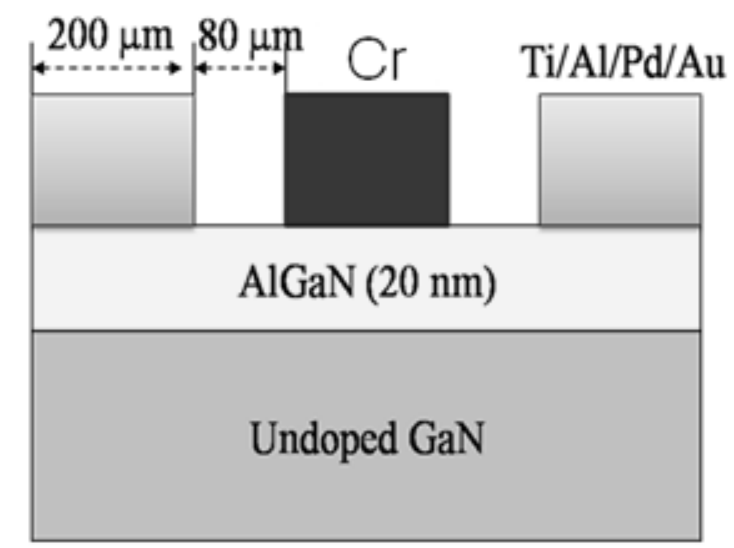

Fig. 1. Cross-sectional diagram for $\mathrm{Cr}-\mathrm{AlGaN} / \mathrm{GaN}$ Schottky contacts.

하였으며, 모두 전자빔 증착기 (electron-beam evaporation system) 챔버에서 진공도 $5 \times 10^{-7}$ Torr 이하에서 증착하였 다. 오믹전극을 먼저 형성시킨 후, 쇼트키 전극을 형성하였 으며, 오믹전극은 RTA (rapid thermal annealing)챔버에서 질소 분위기하에 $600{ }^{\circ} \mathrm{C}, 1$ 분간 열처리하여 얻었으며, 이후 $\mathrm{Cr}$ 쇼트키 전극층을 형성하였다. 전류-전압, 커패시턴스전압 특성은 반도체 분석기 $(\mathrm{HP} 4155 \mathrm{~A})$ 와 $\mathrm{LCR}$ 분석기 (HP4284A)를 이용하여 얻었으며, $\mathrm{Cr}-\mathrm{AlGaN}$ 계면분석은 $\mathrm{Al} \mathrm{Ka} \mathrm{X-ray에} \mathrm{기초한} \mathrm{XPS} \mathrm{(MultiLab} 2000$ 모델)장비를 활용하였다.

\section{3. 결과 및 고찰}

그림 2(a)는 $\mathrm{Cr}-\mathrm{AlGaN} / \mathrm{GaN}$ 쇼트키 접속의 전류-전 압 특성을 보여주는 것으로, 전형적인 정류특성을 갖는 쇼트키 접촉이 형성되었음을 알 수 있다. Thermionic Field Emission (TFE) 방법 [10,11]에 의하여 Schottky barrier height (SBH)와 $2 \mathrm{DEG}$ 성분을 의미하는 $\mathrm{AlGaN}$ 장벽 표면밀도 $\left(\mathrm{N}_{\mathrm{s}}\right)$ 를 계산하였으며, $\mathrm{SBH}$ 는 $1.98 \mathrm{eV}, \mathrm{N}_{\mathrm{s}}$ 는 $8.2 \times 10^{12} \mathrm{~cm}^{-2}$ 이었다. 그림 $2(\mathrm{~b})$ 는 $\mathrm{TFE}$ 방법에 의해서 fitting한 결과를 나타낸 것이다. 쇼트 키 형성 이전 홀측정 결과상으로 $\mathrm{AlGaN} / \mathrm{GaN}$ 층에서 $\mathrm{AlGaN}$ 장벽의 표면밀도는 $1.17 \times 10^{13} \mathrm{~cm}^{-2}$ 이었는데, $\mathrm{TFE}$ 방법에 의하여 얻어진 결과는 쇼트키 접촉 형성 후, 표면밀도가 낮아짐을 알 수 있다. 이러한 결과는 Lin et al. [4] 결과와 일치하며, 따라서 Polarization 영향 과 낮은 일함수를 갖는 금속 사이에서의 wavelength coupling 

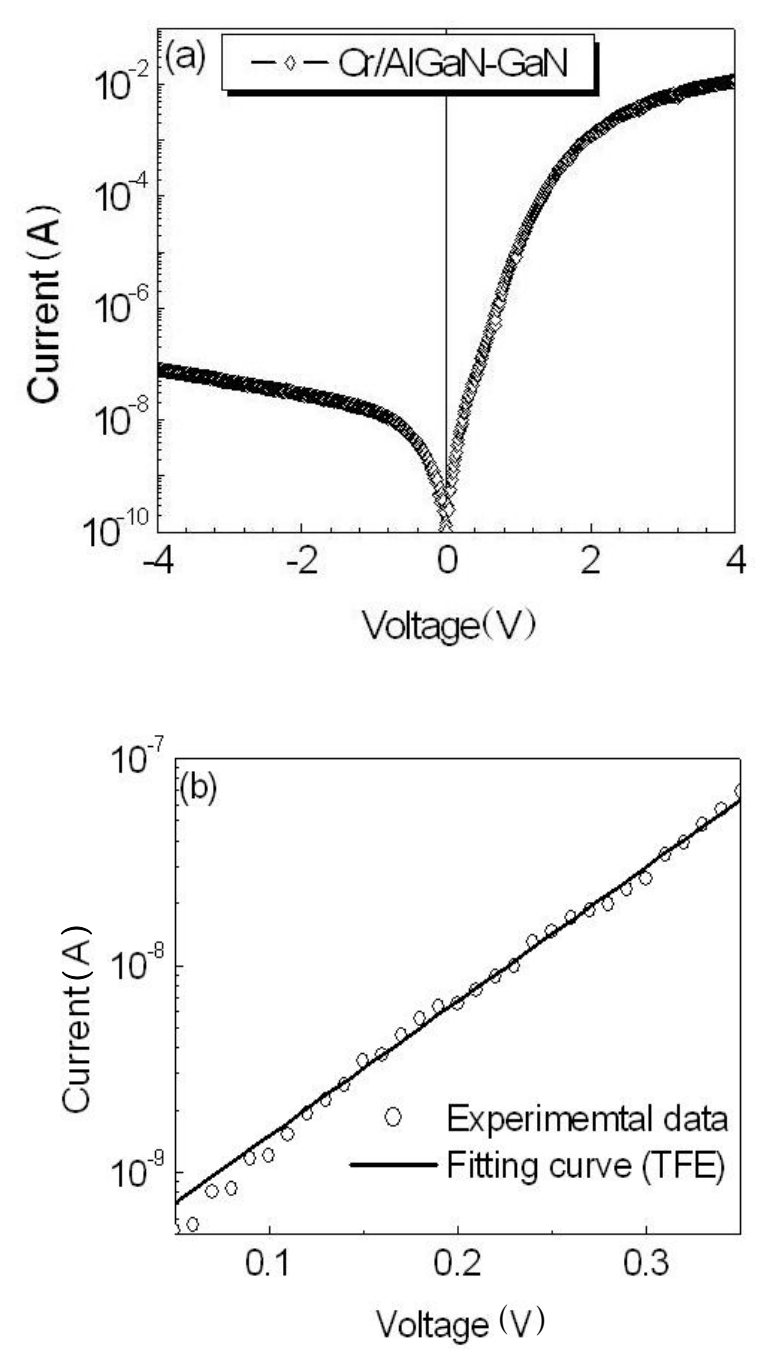

Fig. 2. (a) Current-voltage characteristics of $\mathrm{Cr}-\mathrm{AlGaN} / \mathrm{GaN}$ Schottky contacts and (b) TFE fitting results in the forward bias regions of $0-0.39 \mathrm{eV}$.

작용에 의하여 $\mathrm{SBH}$ 가 증가하는 것 은 Polarization field 영향이 큰 $\mathrm{AlGaN} / \mathrm{GaN}$ 이종접합구조에서 Schotty 장 벽 형성에 영향을 줌을 확인하였다.

본 연구에서는, 전류-전압 특성 자료에 기초한 $\mathrm{TFE}$ 결과와 커패시턴스-전압 특성 자료에 기초한 $2 \mathrm{DEG}$ 계산방법에 의한 결과와 비교하기 위하여 커패 시턴스-전압 특성을 측정하였으며, 결과를 그림 3에 나타내었다. 본 계산에서, 만일 $\mathrm{AlGaN} / \mathrm{GaN}$ 구조에서 Undoped $\mathrm{GaN}$ 의 전자밀도변화가 무시할 수 있을 만 큼 작다면, $2 \mathrm{DEG}$ 전자밀도는 $\mathrm{AlGaN} / \mathrm{GaN}$ 전자표면 밀도와 거의 유사하다고 가정할 수 있으므로, 결국,

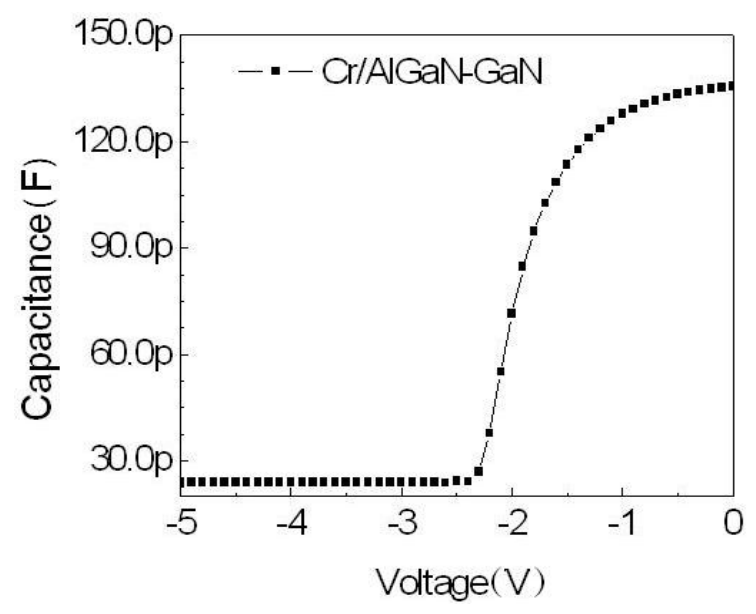

Fig. 3. Capacitance-voltage characteristics of $\mathrm{Cr}-\mathrm{AlGaN} / \mathrm{GaN}$ Schottky contacts.

커패시턴스-전압 특성 Curve를 Integration 함으로써 전자 표면밀도를 계산할 수 있다. 계산된 표면밀도는 $5.8 \times 10^{12} \mathrm{~cm}^{-2}$ 이었다. 이것은 앞서 $\mathrm{TFE}$ 계산결과와 마찬가지로 쇼트키 접촉 후, $\mathrm{AlGaN} / \mathrm{GaN}$ 전자표면밀 도는 Bare $\mathrm{AlGaN} / \mathrm{GaN}$ 과 비교해보았을 때 상당히 낮 아지는 것으로 확인되었으며, 따라서 $\mathrm{AlGaN} / \mathrm{GaN}$ 이 종접합 쇼트키 접촉에서 $\mathrm{SBH}$ 의 변화는 전자표면밀도 와 직접적인 연관이 있음을 알 수 있다 [4].

커패시턴스-전압 특성 자료를 활용하여, $2 \mathrm{DEG}$ 계 산방법에 의하여 $\mathrm{SBH}$ 를 계산하였다. $\mathrm{AlGaN} / \mathrm{GaN}$ 이 종접합구조에서 $2 \mathrm{DEG}$ 전자밀도는 다음과 같은 식으 로 나타낼 수 있다 [12].

$$
\begin{aligned}
\mathrm{N}_{2 D G E}(x)= & \mathrm{a}_{\mathrm{pz}}(x) / \mathrm{q}-\left[\varepsilon_{0} \varepsilon(x) / \mathrm{dq}^{2}\right] \times \\
& {\left[q \Phi_{\mathrm{B}}(x)+\mathrm{E}_{\mathrm{F}}(x)-\Delta \mathrm{E}_{\mathrm{C}}(x)\right] }
\end{aligned}
$$

$x$ 는 $\mathrm{Al}$ 성분 (composition), $\mathrm{a}_{\mathrm{pz}}$ 는 Polarization 전하 밀도, $\mathrm{d}$ 는 $\mathrm{AlGaN}$ 장벽층 두께, $\mathrm{q} \Phi_{\mathrm{B}}$ 는 $\mathrm{SBH}, \mathrm{E}_{\mathrm{F}}$ 는 Fermi level, $q$ 는 전하이며, $\Delta \mathrm{E}_{\mathrm{C}}$ 는 $\mathrm{AlGaN} / \mathrm{GaN}$ 계면 에서의 Conduction band offset이며, 다음과 같이 정 의한다 [13].

$$
\Delta \mathrm{E}_{\mathrm{C}}(x)=0.7 \times\left[\mathrm{E}_{\mathrm{g}}(x)-\mathrm{E}_{\mathrm{g}}(0)\right]
$$

$\mathrm{E}_{\mathrm{g}}(x)$ 는 $\mathrm{AlGaN}$ 장벽층에서의 에너지 밴드갭이며, $\mathrm{E}_{\mathrm{g}}(x)$ 는 $\mathrm{E}_{\mathrm{g}}(x)=6.13 x+3.42(1-x)-x(1-x)[\mathrm{eV}]$ 이다. (1)과 (2) 식에서, $\mathrm{E}_{\mathrm{F}}(x)$ 와 $\mathrm{E}_{\mathrm{g}}(0)$ 는 다음과 같이 정의한다 $[14,15]$. 


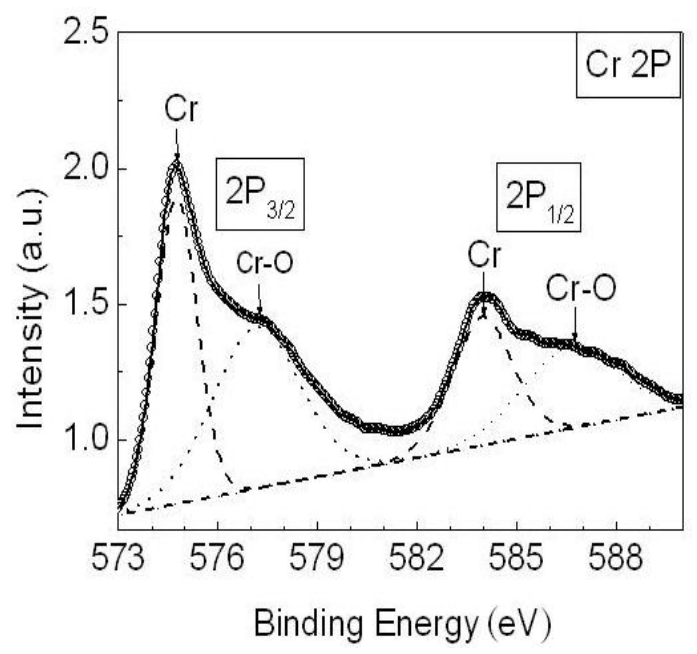

Fig. 4. $\operatorname{Cr} 2 p$ core level peaks obtained from the $\mathrm{Cr}-\mathrm{AlGaN} / \mathrm{GaN}$ interface, showing the formation of $\mathrm{Cr}-\mathrm{O}$ chemical bonding as well as Cr peak.

$$
\begin{aligned}
& \mathrm{E}_{\mathrm{F}}(x)=\mathrm{E}_{0}(x)+\left[h^{2} / 4 \pi m^{*}(\mathrm{x})\right] \times \mathrm{N}_{2 \mathrm{DGE}}(x) \\
& \mathrm{E}_{0}(x)=\left[9 h^{2} q^{2} \mathrm{~N}_{2 \mathrm{DGE}}(x) / 32 \pi\left(8 m^{*}(\mathrm{x})\right)^{0.5} \varepsilon(x)\right]^{2 / 3}
\end{aligned}
$$

여기서, $h$ 는 플랑크 상수, $m^{*}$ 전자유효질량이다. (1)-(4)식을 통하여, $\Delta \mathrm{E}_{\mathrm{C},} \mathrm{E}_{\mathrm{F}}$ 는 $x$ 가 0.25 일 때, 각각 $0.343 \mathrm{eV}$ 와 $0.23 \mathrm{eV}$ 로 계산되었다. 이러한 파라미터 들을 이용하여 얻어진 $\mathrm{SBH}$ 는 $2.08 \mathrm{eV}$ 이었으며, $\mathrm{TFE}$ 방법에 기초해서 얻어진 값 $(=1.98 \mathrm{eV})$ 보다 약간 높 은 값을 보였다.

$\mathrm{Cr}-\mathrm{AlGaN} / \mathrm{GaN}$ 쇼트키 접촉에서 일반적으로 $\mathrm{Al}$ 성분이 25\%일 때에 Polarization-free구조에서의 $\mathrm{SBH}$ 는 "q $\Phi_{\mathrm{Cr}}(4.5 \mathrm{eV})$ - qXAlGaN $(3.6 \mathrm{eV})$ "에 의해서 0.9 $\mathrm{eV}$ 로 계산된다. 이점을 고려해 본다면, Polarization field 영향이 강한 $\mathrm{AlGaN} / \mathrm{GaN}$ 이종접합구조에서 얻 어진 $\mathrm{SBH}$ 는 매우 큰 값을 가짐을 알 수 있으며, 이 것은 Polarization 영향에 의해서 $\mathrm{AlGaN}$ 전자표면밀 도가 낮아지는 현상만으로는 설명하기 부족하다.

따라서, 높은 값을 갖는 $\mathrm{SBH}$ 의 원인을 규명하기 위 해서 XPS (X-ray photoelectron spectroscopy)분석을 시행하였다. 그림 4 는 $\mathrm{Cr}-\mathrm{AlGaN} / \mathrm{GaN}$ 계면에서 얻어 진 $\mathrm{Cr} 2 p$ core level peak을 관찰한 것이다. $\mathrm{Cr}$ peak 외에 $\mathrm{Cr}-\mathrm{O}$ 화학결합 성분이 함께 존재함을 알 수 있 으며, 이것은 $\mathrm{AlGaN} / \mathrm{GaN}$ 이종접합 구조 내에 존재하 는 산소의 영향임을 알 수 있다. 물론, $\mathrm{AlGaN} / \mathrm{GaN}$ 구

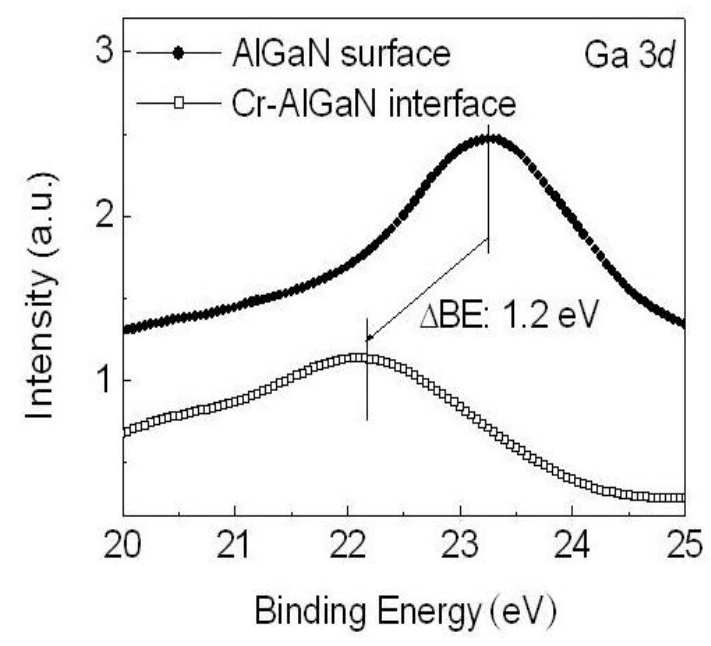

Fig. 5. Ga $3 d$ core level peaks at the interface between $\mathrm{Cr}$ and $\mathrm{AlGaN} / \mathrm{GaN}$.

조위에 존재하는 자연산화층의 영향일수도 있지만, 이 것은 $\mathrm{Cr}$ 층을 증착하기 전에 충분히 염산수로 표면처 리 하였고, XPS 분석 시, 표면처리 된 $\mathrm{AlGaN}$ 표면에 산소가 검출되지 않았기 때문에 자연산화층에 기인한 영향이기 보다는 $\mathrm{AlGaN}$ 층 내에 존재하는 산소와 $\mathrm{Cr}$ 이 상호 결합한 결과라고 해석하는 것이 보다 정확한 설 명이다. $\mathrm{Cr}-\mathrm{O}$ 형성은 그림 5 에서와 같이, $\mathrm{Ga} 3 d$ peak의 low binding energy 방향으로 $1.2 \mathrm{eV}$ Peak shift를 유발 하며, 이것은 표면 Fermi level이 $\mathrm{Cr}$ 과 $\mathrm{AlGaN} / \mathrm{GaN}$ 접촉 후 이동한 것으로 볼 수 있다. 따라서, Polarization-free $\mathrm{AlGaN}$ 구조와는 달리, Polarization field에 영향을 받는 $\mathrm{AlGaN} / \mathrm{GaN}$ 이종접합구조에서는 $\mathrm{AlGaN}$ 층 내에 존재하 는 산소의 영향으로 인한 $\mathrm{Cr}-\mathrm{O}$ 화학결합 형성, 표면 Fermi level 이동, 전자표면밀도의 감소에 의해서 $\mathrm{SBH}$ 가 결정됨을 알 수 있다. 사실, $\mathrm{AlGaN} / \mathrm{GaN}$ 내에 존재하는 산소는 donor로서의 역할을 하는데 [9], $\mathrm{Cr}-\mathrm{O}$ 화학결합 형성은 $\mathrm{AlGaN}$ 표면에서의 도너전자 수를 감소시켜 전자 표면밀도가 낮아지는 것으로도 설명할 수 있다.

\section{4. 결 론}

$\mathrm{Cr}$ 을 이용하여 $\mathrm{AlGaN} / \mathrm{GaN}$ 쇼트키접촉을 구현하였 다. $\mathrm{TFE}$ 방법과 $2 \mathrm{DEG}$ 방법에 의하여 얻어진 $\mathrm{SBH}$ 는 각각 $1.98 \mathrm{eV}$ 와 $2.08 \mathrm{eV}$ 이었으며, 이는 Polarizationfree $\mathrm{AlGaN}$ 구조에서 얻어진 $0.9 \mathrm{eV}$ 보다 높은 값을 
나타내었다. XPS 분석을 통하여, 높은 $\mathrm{SBH}$ 형성원인 이 $\mathrm{AlGaN} / \mathrm{GaN}$ 구조에서 $\mathrm{AlGaN}$ 전자표면밀도의 감 소, 계면에서 $\mathrm{Cr}-\mathrm{O}$ 화학결합형성 및 표면 Fermi level 의 발런스 밴드 방향으로의 이동에 의한 것임을 알 수 있다. 본 연구결과는 고성능 전자소자 구현에 있어 고 품질 Schottky gate개발에 큰 기여를 할 것으로 기대 된다.

\section{감사의 글}

본 연구는 영남대학교 연구조교지원사업과 지식경 제부 산업원천기술과제 LED-IT융합산업화연구센터 (과제번호 10033630) 지원에 의하여 수행되었음.

\section{REFERENCES}

[1] M. A. Khan, Q. Chen, M. S. Shur, B. T. MsDermott, and J. A. Higgins, IEEE Electron Device Lett. 17, 325 (1996).

[2] E. J. Miller, X. Z. Dang, and E. T. Yu, J. Appl. Phys. 88, 5951 (2000).

[3] A. J. Sierakowski, W. J. Scharff, and L. F. Eastman, J. Appl. Phys,. 87, 334 (2000).

[4] Z. Lin, W. Lu, J. Lee, D. Liu, J. S. Flynm, and G. R. Brandes, Appl. Phys. Lett., 82, 4364 (2003).
[5] O. Ambacher, J. Smart, J. R. Shealy, N. G. Weimann, K. Chu, M. Murphy, W. J. Scharff, L. F. Eastman, R. Dimitrov, L. Wittmer, M. Stutzmann, W. Rieger, and J. Hilsenbeck, J. Appl. Phys., 85, 3222 (1999).

[6] J. P. Ibbetson, P. T. Fini, K. D. Ness, S. P. DenBarr, J. S. Speck, and U. K. Mishra, Appl. Phys. Lett.,. 77, 250 (2000).

[7] Z. Lin, J. Lee, and W. Lu, Appl. Phys. Lett.,. 84, 1585 (2004).

[8] C. M. Jeon and J. R. Lee, Appl. Phys. Lett. 82, 4301 (2003).

[9] H. W. Jang, J. M. Baik, M. K. Lee, H. J. Shin, and J. L. Lee., Electrochem. Solid-State Lett., 151(8), G536 (2004).

[10] J.-S. Jang, T.-Y. Seong, and S.-R. Jeon, Electrochem. Solid-State Lett., 10(4), H120 (2007).

[11] J.-S. Jang, D. Kim, and T.-Y. Seong, J. Appl. Phys. 99, 073704 (2006).

[12] E. T. Yu, G. J. Sullivan, P. M. Asbeck, C. D. Wang, D. Qiao, and S. S. Lau, Appl. Phys. Lett. 71, 2794 (1997).

[13] G. Martin, A. Botchkarev, A. Rockett, and H. Morkoc, Appl. Phys. Lett. 68, 2541 (1996).

[14] D. Bruuner, H. Angerer, E. Bustarret, R. Hopler, R. Dimitrov, O. Ambacher, and M. Stutzmann, J. Appl. Phys, 82, 5090 (1997).

[15] M. Shur, Mater. Res. Soc. Symp. Proc. 483, 15 (1998). 